\title{
LA IDENTIDAD DEL “OCTAVO” EN APOCALIPSIS 17:11
}

\author{
ERIK JiMÉnEZ MiLla \\ DOCENTE DE LA FACULTAD DE TEOLOGIA - UPEU
}

Como presentamos en un anterior artículo, ${ }^{1}$ la mayoría de eruditos de la escuela historicista, como Kenneth A. Strand, Louis Were, C.M. Maxwell y otros, interpretan que las siete cabezas y los siete montes son imperios y no reyes específicos. ${ }^{2}$

Apocalipsis 17:9 dice que las "siete cabezas" de la bestia son siete montes y siete reyes. La clave para no desviarse al querer encontrar los nombres de los montes o personajes históricos, lo da el mismo capítulo, cuando el ángel interpreta un elemento de la naturaleza en forma simbólica al decir: "las aguas son naciones, pueblos, muchedumbre" (v. 15). Entonces este punto de interpretación directa determina que cualquier otro elemento de la naturaleza que contenga este pasaje no debe ser interpretado en forma literal, sino simbólica. Esto quedó bien marcado en el artículo anterior pues se trata de siete reinos. Aparentemente todo queda resuelto al descubrir los siete imperios de la historia profética, pero no es así: sucede algo inesperado.

El versículo 11 declara: "Y la bestia que era y ya no es, es también el octavo, y es de los siete, y va a su destrucción". Si la Bestia en todas sus apariciones apocalípticas tiene siete cabezas (Ap12, 13 y 17), ¿por qué se introduce ahora un aparente "octavo"?

El objetivo de este artículo es identificar al "octavo" dentro del contexto de la bestia de siete cabezas y diez cuernos. Una primera hipótesis es que no se trata de un reino más, sino de una acción de la bestia. Por

${ }^{1}$ Para un mayor estudio, ver Erik Jiménez Milla, “¿Cuatro o siete imperios universales?”, Estrategias 6, no. 2 (2009): 37-48.

${ }^{2}$ Hans LaRondelle, Las Profecías del fin, trad. David Gullón (Buenos Aires: Asociación Casa Editora Sudamericana, 1999), 418. Por esta razón, las interpretaciones que presentan a emperadores o papas tendrían que revisar el trasfondo profético descrito en el mismo Apocalipsis y en Daniel. 
otro lado, el "octavo" tiene relación con la acción del Anticristo y su acto final en su afán de engañar a la humanidad. Por último, "el octavo" al ser diferente y no ser un reino más, debe tener un significado más amplio.

Este estudio se desarrolla tomando, en primer lugar, la traducción del texto, para después hacer un desarrollo de la expresión "octavo" en toda la Biblia. Después, presenta el pensamiento de algunos estudiosos acerca de este problema, para finalmente, utilizando un estudio bíblico teológico de la expresión "octavo", llegan a descubrir el énfasis bíblico de esta expresión.

\section{¿Qué dice el texto?}

En el versículo 11 hay tres variantes textuales (diferencias entre los manuscritos bíblicos) en esta frase: una de omisión, otra de sustitución y una de adición. ${ }^{3}$ Por lo que el texto tiene una traducción diferente, ya no sería "y es el octavo", sino, "este es el octavo". Esta nueva perspectiva hace que sea nominal.

Las cabezas, que son presentadas en forma consecutiva o numeral, tienen un sentido de género femenino y era de esperar que "la octava" mantuviera esta misma expresión y por ende vendría a ser parte de la misma esencia. Pero no es así, "el octavo", como dice el texto, es de género masculino. Esto lo hace distinto. Sugiriendo con esto que no se refiere a la continuación de las cabezas, sino a un elemento o circunstancia distinta y que no es una cabeza más en la secuencia histórica de los reinos, considerando que no hay posibilidad de una bestia con ocho cabezas.

Si se observa con cuidado, no está proponiendo el texto a otro reino, sino que está describiendo a "octavo" como que siempre existió

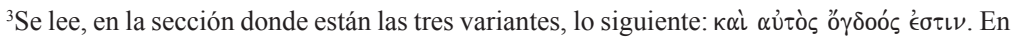
esta oración, en el manuscrito mayúsculo $x$, y en el manuscrito Vercellensis (del s. IV d.C.), se ha omitido la conjunción $\kappa \alpha$. Además, se ha sustituido en los manuscritos, tanto mayúsculos y minúsculo, como en el $1006.1841 .2030 \mathrm{sy}^{\mathrm{h}}$, el pronombre personal $\alpha$ ủtò

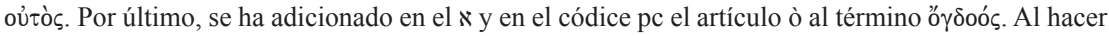
las modificaciones del caso, puesto que las variantes están en los manuscritos más antiguos, creyen-

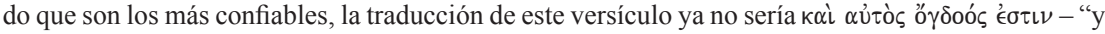

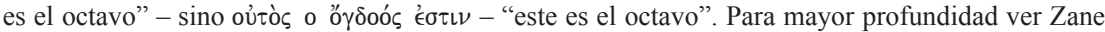
Clark Hodges, Arthur L. Farstad and William C. Dunkin, The Greek New Testament According to the Majority Text, 2nd ed. (Nashville: T. Nelson Publishers, 1985), 777. 
entre los siete reinos bestiales y que al final del séptimo reino hace su aparición, se pone en acción, sale del abismo, "será", y cuando sale a la luz, realiza su obra final y le espera la perdición.

\section{Perspectivas de algunos estudiosos}

Para Máximo Vicuña el artículo definido está ausente delante de la palabra octavo sugiriendo con esto que se refiere a la bestia misma, o sea a Satanás (Ver. 3). Las siete cabezas son visibles, en cambio el octavo "ha de subir del abismo" (ver. 8). De Satanás se dice que saldrá de la tierra (abismo) al fin del milenio (Ap 20:7-9). ${ }^{4}$

Jacques Doukhan parece tener la misma posición pero con ciertos detalles. $^{5}$ Comienza haciendo una relación de las características de la bestia (era, ya no es, y será) con las características de Jesús en Apocalipsis $(4: 8$; cf. 1:4, 8), diciendo que con esto confirma la ambición de la bestia de reemplazar la Adoración a Dios para sus propios fines.

LaRondelle comienza a ver el misterio de esta aparente octava cabeza, desde la perspectiva del mismo texto. Para él, la combinación de las declaraciones finales: "está por subir del abismo"(17:8a); “y reaparecerá" (17: 8c, JS, BJ); "es también el octavo"(17:11), relacionan al "octavo" con la reaparición de la bestia, después de salir del abismo. LaRondelle lo llama: "la resurrección de la bestia". Toma el significado del número 8 , diciendo que es el número de la resurrección!. ${ }^{6}$

Siguiendo el mismo esquema del artículo anterior, se tratará de establecer, cuál es motivo por el cual algunos autores lo relacionan al número ocho con "la resurrección", "Jesús", "la circuncisión", entre otras denominaciones. Todo ello con la finalidad de no simplemente decir este número representa tal o cual cosa sino, basado en un estudio bíblico teológico, para respaldar la declaración que se dé. Siendo que la explicación del "tres" y del "siete", ayudó a una mejor comprensión en la identidad de las tres expresiones de la bestia ("era", "ya no es" y "será") y de las siete

\footnotetext{
${ }^{4}$ Máximo Vicuña, Interpretación histórica del libro de Apocalipsis (Lima: Editorial Imprenta Unión, 1989), 133.

${ }^{5}$ Doukhan, Secrets of Revelation, 161-4.

${ }^{6}$ LaRondelle, Las profecias del fin, 422-3.
} 
cabezas, se cree que también lo hará la profundización bíblica del "ocho".

\section{Significado del número "ocho"}

¿Qué significa el número “ocho” en la Biblia? El primer hecho que relacionamos a este número es la referida al número de humanos que entraron al arca en el diluvio. Pedro registra de una manera interesante al decir que tan sólo ocho personas se salvaron del diluvio (1 P 3:20). Pero qué tiene que ver el arca con la resurrección o Jesús. El comentario Bíblico Adventista explica esta relación de la siguiente manera:

Las aguas del diluvio, que sepultaron a los pecadores que "desobedecieron" en los días de Noé, fueron el medio para salvar a los que estaban dentro del arca de salvación, y así se les conservó la vida. La salvación "por agua" de esas "ocho... personas" y la razón de Pedro para insertarlo, es el clímax de este paréntesis un poco extenso en cuanto a los antediluvianos. La lección que se deduce de este episodio se expresa en el vers. 21: Así como "fueron salvados por agua", así también" el bautismo... ahora nos salva". Pero tanto esos "ocho" antediluvianos como los cristianos son igualmente salvados en virtud de la resurrección de Cristo de los muertos (ver com. vers. 19, 2 1), pues de otra manera no habría esperanza para ninguno de esos grupos (ver 1 Cor. 15:13-23). ${ }^{7}$

La relación que surge en la salvación de las personas en el diluvio con el bautismo y la resurrección, y la forma indirecta en que aparece el "ocho", comienza a sentar las bases de una relación bastante extraña.

Pero no es todo. Los siete días que Noé estuvo dentro del arca, antes de que llegara la lluvia, llegando a llover después de siete días, es algo que también tiene relación. Para Skinner la secuencia de eventos es la siguiente: Al final de los siete días, viene el diluvio (v. 10); En esos días, Noé está dentro del arca (v. 7) y el Señor había cerrado la puerta detrás de Noé (16b). ${ }^{8}$ Esto nos lleva a considerar que al octavo día viene

${ }^{7} C B A, 7: 592$.

${ }^{8}$ John Skinner, A Critical and Exegetical Commentary on Genesis (New York: Scribner \& 
el diluvio. Elena G. de White lo confirma de la siguiente manera:

Durante siete días después que Noé y su familia hubieron entrado en el arca, no aparecieron señales de la inminente tempestad... La aparente tardanza confirmaba la creencia de que el mensaje de Noé era un error y que el diluvio no ocurriría. Pero al octavo día obscuros nubarrones cubrieron los cielos. Y comenzó el estallido de los truenos y el centellear de los relámpagos. ${ }^{9}$

Es interesante que el inicio del caer de las aguas "bautismo", se dé el "octavo" día. Esto podría indicar que la nueva etapa en la existencia de la tierra, se iniciaría después de siete días de descanso. La siguiente figura puede ilustrar lo que se quiso decir:

Diagrama 1: Los ochos días en el arca

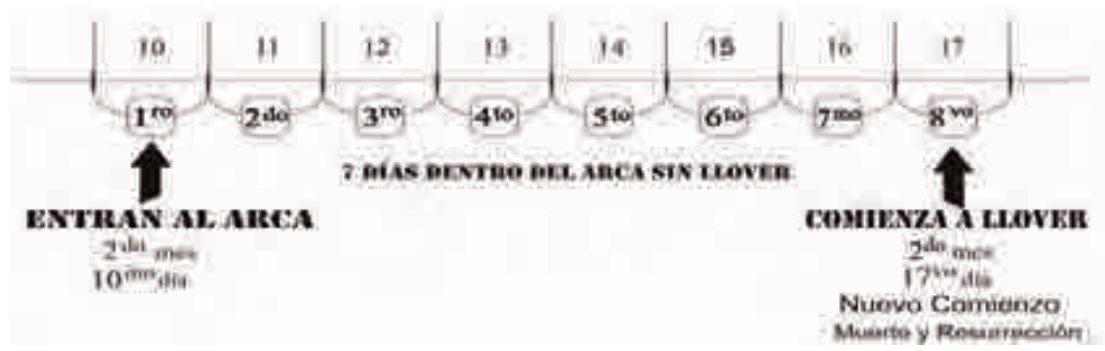

Después se encuentra la descripción referida a la circuncisión, hecha al octavo día de nacido todo niño varón (Gn 17:2). Lucas lo registra así: “...y lo circuncidó al octavo día”(Hch 7:8). El símbolo que inicia este proceso tiene relación directa con los primogénitos. El primer modelo de ofrenda de sacrificio a Dios es enseñado por Abel, ya que su ofrenda era el primogénito y el mejor de todas sus ovejas (Gn 4:4).

Más adelante, Moisés ordena que los primogénitos tanto hombres como animales debieran ser consagrados a Dios. El procedimiento para la separación del primogénito se dio en el Sinaí. Los primogénitos debían estar con su madre siete días y el octavo día debía ser entregado a Dios.

Sons, 1910), 152.

${ }^{9}$ White, Patriarcas y profetas, 87. 
Tal como se afirma en Éxodo 22: 29b-31a, esto también se hacía con los bueyes y con las ovejas. La expresión "Siete días estará con su madre, y al octavo día me lo darás. Y seréis para mí hombres santos”, se puede ilustrar de la siguiente manera:

Diagrama 2: La separación de los primogénitos al octavo día

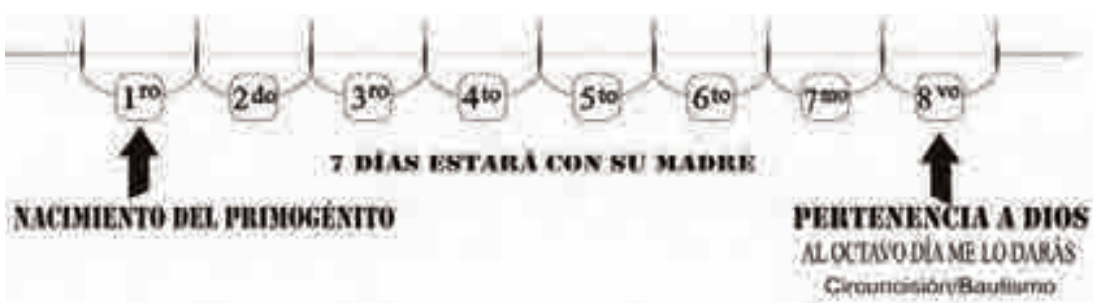

Hay una aclaración que se debe dar, es que el conteo para los judíos y otras naciones antiguas era con el método inclusivo. ${ }^{10}$ Es decir se contaba el día que era mencionado el evento, al contrario de nosotros que contamos después del día señalado.

Un acontecimiento muy significativo, referente también a la circuncisión y al nuevo nacimiento (el bautismo) es el cruce del Mar Rojo. Este hecho tiene un significado especial, llegaría a ser para todo judío como un símbolo de purificación. Así lo explica el siguiente comentario:

También se lo consideraba como el repaso de uno de los acontecimientos que hizo de Israel una nación: el cruce del Mar Rojo. Junto con la circuncisión y los sacrificios hacían del prosélito un integrante del mismo pacto del que participaban los israelitas de nacimiento. El estatus legal de este prosélito era el de un recién nacido (cf Jn. 3:3-10). ${ }^{11}$

Siendo que este acontecimiento llegaba a significar algo tan espe-

10“'Como ya se señaló (ver t. I, pág. 191), el método de computar el tiempo comúnmente usado en la Biblia parece haber sido el cómputo inclusivo, es decir, se contaba tanto la primera unidad de tiempo como la última al calcular la duración de un intervalo. Este método también era corriente en otras naciones de la antigüedad, según lo atestiguan sin lugar a duda ciertos documentos. $C B A, 2: 139$.

${ }^{11}$ Diccionario Bíblico Adventista del Séptimo Día, 145. 
cial, los detalles del mismo son necesarios. Pablo dice en forma figurada de la experiencia de Israel al salir de Egipto: "en Moisés todos fueron bautizados en la nube y en el mar" (1 Co 10: 2). La circuncisión era un rito relacionado con el pacto. Era la señal del pacto con el Israel literal, mientras que el bautismo llegó a ser con el Israel espiritual (ver Gn 17: 11; Col 2: 11, 12; Tit 3: 5; 1 P 3: 21).

La pascua tiene una relación con el cruce del mar rojo. Esta fiesta se celebró por primera vez con la salida del pueblo hebreo de Egipto. Pero estaba dentro de un esquema de siete días. En estos 7 días previos estaba incluida la muerte de los primogénitos que cayó en día sexto, 14 de Aviv y la salida al desierto desde Ramesés, el séptimo día, 15 de Abib. Tal como se afirma el texto de Números 33: 3-5.

Pero esta relación del bautismo y el cruce del Mar Rojo no es ninguna sorpresa, ya que en el proceso de redención tiene una conexión perfecta. Entonces el cruce del Mar Rojo, presenta dos posibilidades. La primera, aunque hay mucha incertidumbre, debe haber sido al octavo día, al tercer día de la pascua (método inclusivo) cuando ellos son librados de la mano de sus opresores. El siguiente diagrama ilustra esta primera posibilidad.

Diagrama 3: El cruce del mar rojo al 8vo día - I.

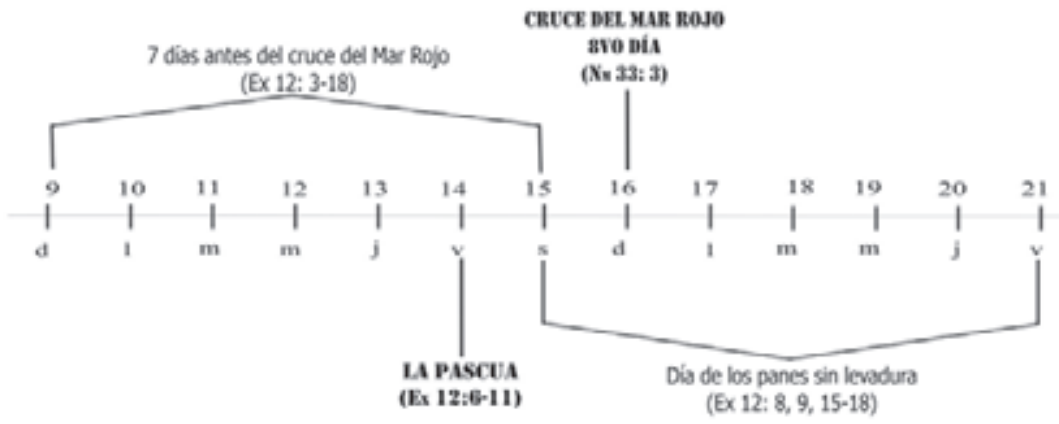

La segunda posibilidad y la más segura, se da en conexión a la consagración de los primogénitos, y el asunto relacionado con los siete días que debían comer panes sin levadura, como un símbolo de su liberación. Es después de siete días, contados del día 15 de Abid, llegando 
hasta el 21, y el día de cruce del mar rojo el día 22 de Abid.

Apoya este argumento la descripción del recorrido, resumido en el libro de Números ${ }^{12}$, siendo que acamparon en dos lugares cuando la orden había sido que caminaran sin detenerse, tanto en la noche como en el día, y que la columna de fuego servía para la noche y la nube en el día (Ex 13 :21). Es que el avance habría tenido que ser regular, mientras los egipcios lloraban y enterraban a sus primogénitos. Entonces la fecha sería el 22 de Abid. El diagrama así sufre una pequeña modificación.

Diagrama 4: El cruce del mar rojo al 8vo día - II.

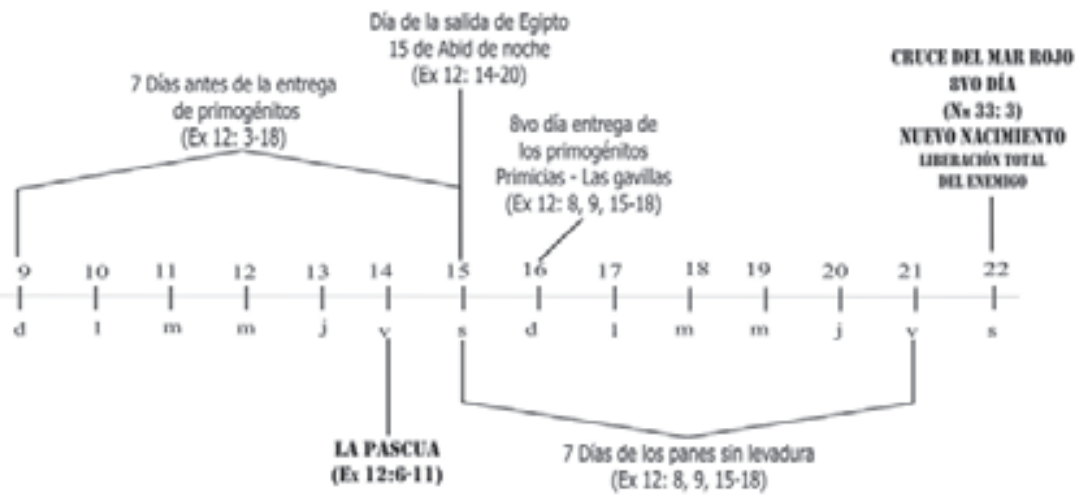

La segunda fiesta, después de la Pascua, es la fiesta de las siete semanas, o llamada la fiesta del Pentecostés. ${ }^{13}$ Esta fiesta también nos da una mención indirecta al octavo como día de celebración de la cosecha. Así como se contaron dos semanas de siete días para que luego, al octavo día, sucediera el cruce del mar rojo, también en esta fiesta se contaban las semanas; esta vez son siete semanas, hasta el día siguiente del séptimo

12“"Partieron de Sucot y acamparon en Etam, que está en el extremo del desierto. Partieron de Etam, se volvieron a Pi-hahirot, frente a Baal-Zefón, y acamparon delante de Migdol. Partieron de delante de Hahirot y pasaron por en medio del mar al desierto" (Nm 33: 6-8).

13"Siete semanas contarás; comenzarás a contar siete semanas desde el momento en que empieces a meter la hoz a la mies. Entonces celebrarás la fiesta de las semanas al SEÑOR tu Dios con el tributo de una ofrenda voluntaria de tu mano, la cual darás según el SEÑOR tu Dios te haya bendecido" (Dt 16: 9-10). 
feriado, haciendo un total de cincuenta días. Se presentaban los primeros frutos de la cosecha de trigo (Ex 34: 22; Lv 23: 1-16; Nm 28: 26). Se la conocía como "día de las primicias". Se contaba desde el día que se ofrece la gavilla de la ofrenda mecida (Lv 23: 15-17). Entonces la relación de un octavo al final de las siete semanas es encajada como un símbolo de primicias (primogénitos, circuncisión, etc). Era el día en que los primogénitos tenían que presentarse ante Dios. Así como un día hemos de presentarnos a Jesús, en ocasión de su segunda venida.

Esta fiesta era muy solemne Jesús la mandó a cumplir a sus apóstoles y les ordenó, que después de 50 días de su muerte, él derramaría su Espíritu sobre ellos. Sería el día de encuentro con Dios. Iniciarían después de allí, el establecimiento de la iglesia cristiana, que tendría la meta de llegar a todo el mundo.

Diagrama 5: El pentecostés y el 8vo día

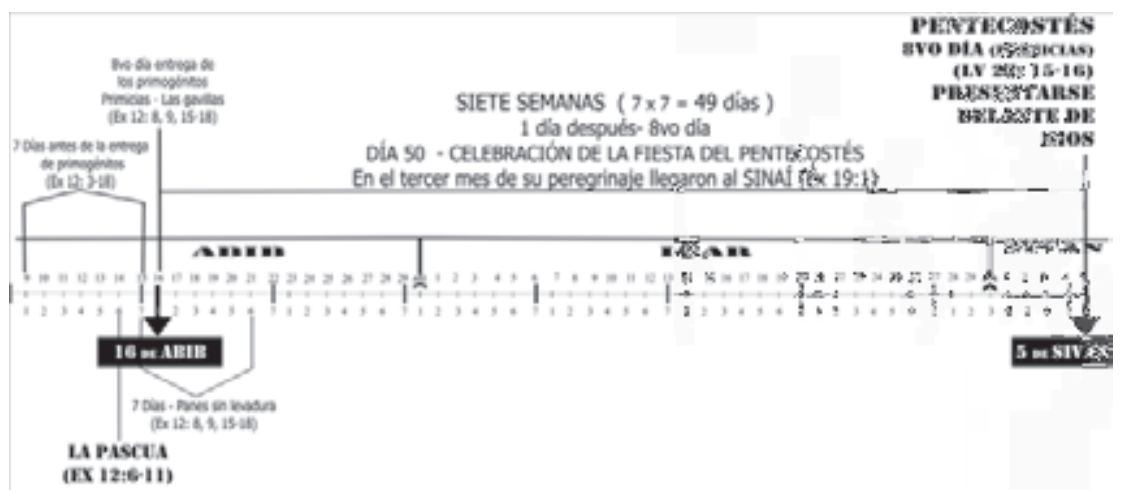

La siguiente fiesta a mencionar, en la relación con el octavo, es la fiesta de las cabañas. Era una fiesta de felicidad plena. La cosecha había terminado, la alegría se compartía con los hijos, los siervos, el levita, el extranjero y la viuda (Dt 16: 16). Según Merling Alomía, tenía una connotación salvífica vinculada con la conmemoración del cuidado que Dios 
extendió en sus años de peregrinación. ${ }^{14}$

De hecho, aunque esta fiesta, de modo oficial tuvo el mismo rango que la Pascua y Pentecostés, la fiesta de las Cabañas jugó un rol mucho mayor en la vida del pueblo que las otras dos, a tal punto que cuando la gente decía "la Fiesta", sin especificar ninguna otra cosa, simplemente se estaban refiriendo a la de las Cabañas. En realidad, aunque la Pascua llegó a ser la fiesta nacional más importante para los hebreos, la fiesta de las Cabañas, sin embargo, permaneció como la más festiva y más gozosa de todas las fiestas. $^{15}$

Esta fiesta comenzaba con un primer día de reposo y terminaba con el octavo día también como feriado. Para Alomía, esta fiesta tiene una significación netamente escatológica, pues señala el mismo momento de la restauración de los "cielos nuevos y tierra nueva" que Jehová hará tras la eliminación del pecado y los pecadores mediante el día en que la tierra arda hasta el punto en que los elementos ardiendo sean deshechos. ${ }^{16}$

Un detalle que se ve en esta fiesta, es que Jesús mismo la celebró cuando estuvo aquí en la tierra. Sus hermanos intentaron persuadirle para que no esté en esa fiesta por peligro de que lo mataran (Jn 7: 3), pero se quedó, aunque en secreto (Jn 7: 10). Luego a mediados de la fiesta, Jesús se mostró y comenzó a enseñar. El último día de la fiesta, Jesús proclamó: "Si alguno tiene sed, que venga a mí y beba" (Jn 7:37).

Esta referencia da entonces una conexión especial, antecediendo lo que dice Apocalipsis: "Entonces oí una gran voz que decía desde el trono: He aquí, el tabernáculo de Dios está entre los hombres, y él habitará entre ellos y ellos serán su pueblo y Dios mismo estará entre ellos" (Ap 21: 3). La simbología de esta fiesta por ende es la más importante de lo visto hasta aquí, ya que considera el establecimiento del reino de Dios con "cielos nuevos y tierra nueva". Lo importante, en lo que tiene relacionado con la expresión "octavo", es que aquí ya se vislumbra el

\footnotetext{
${ }^{14}$ Alomía, El año agradable de Jehová, 94.

${ }^{15}$ Alomía, El año agradable de Jehová, 96.

${ }^{16}$ Ibid., 164. 
inicio de un nuevo reino, el reino de Cristo, el octavo reino que jamás será destruido. El siguiente diagrama presenta un resumen que intenta graficar cada cosa dicha hasta aquí.

Diagrama 6: La fiesta de las cabañas y su relación con el 8vo

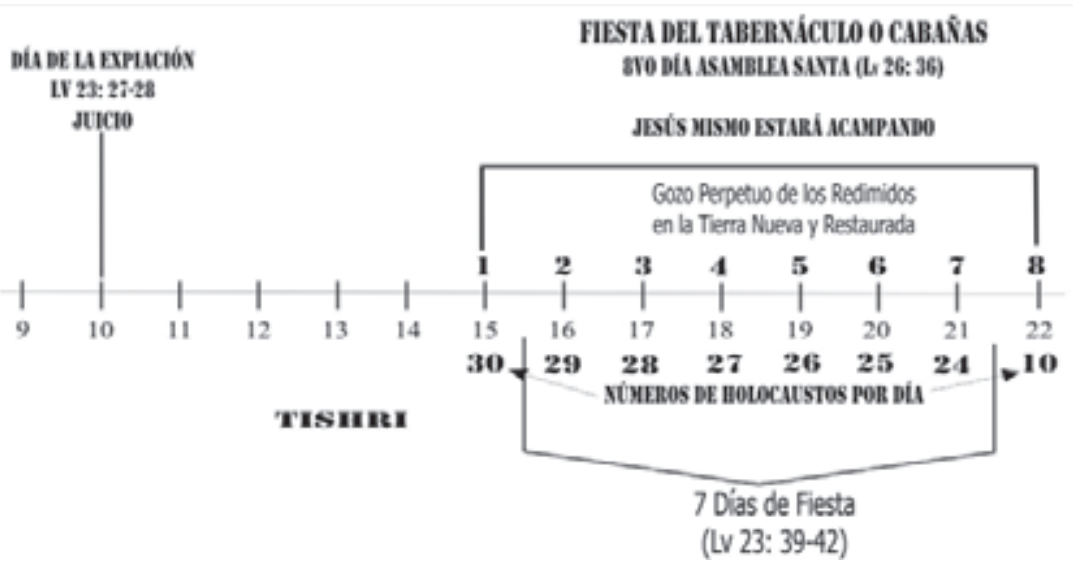

Otra referencia al octavo, como restauración, resurrección, bautismo, primicias, gozo perpetuo, es la que se presenta como el año del jubileo. Aunque no era una fiesta era un evento con gran significancia. Estaba unida, como lo estaba el Pentecostés, a siete períodos de siete, pero en este caso no eran días sino años. Se lo llamaba el año sabático, y consistía en que cada seis años, debía la tierra descansar un año (Lv 25: 3-4). Y tendrían que pasar siete semanas, cuarenta y nueve años, para el jubileo, es decir el año cincuenta, el cual aparte del último año, el séptimo año de reposo, el octavo también sería libre. A ese octavo año se lo llama el año del jubileo.

Esta festividad que se celebraba cada cincuenta años, tenía un énfasis no sólo de descanso sino de santificación: "Y santificaréis el año cincuenta, y pregonaréis libertad en la tierra a todos sus moradores; ese año os será jubileo, y volveréis cada uno a vuestra posesión, y cada cual volverá a su familia" (Lv 25: 10). Para Alomía, es imposible dejar de vislumbrar en el jubileo dos aspectos significativos, a saber libertad y restauración.

La libertad era un asunto vinculado íntimamente con la experiencia de Israel pues pasaron siglos de esclavitud en tierra extraña, 
de modo que era inconcebible tener israelitas esclavos en la tierra de Israel. En tanto que la restauración, además de declarar el ideal de la nación se remonta a proporciones escatológicas cuando la restauración de la nación sea plena bajo el dosel del reino mesiánico. Así, el jubileo fue establecido por Jehová para representar la intervención mesiánica final de redención y restauración cuando él reine supremo con sus santos". ${ }^{17}$

Como dice esta declaración, el jubileo fue instaurado para representar la intervención final de Jesús. Fue el mismo Jesús, quien dijera: "El Espíritu del Señor está sobre mí, porque me ha ungido para anunciar el evangelio a los pobres. Me ha enviado para proclamar libertad a los cautivos, y la recuperación de la vista a los ciegos; para poner en libertad a los oprimidos; para proclamar el año favorable del Señor (Lc 4:18-19). Este año favorable anunciaba la inauguración del Reino de Dios, que se iniciaba con la venida del Mesías encarnado. Pero esta figura llevaba una proyección, al momento cuando Jesús instaure su reino final. ${ }^{18}$

Diagrama 7: El Jubileo y el 8vo

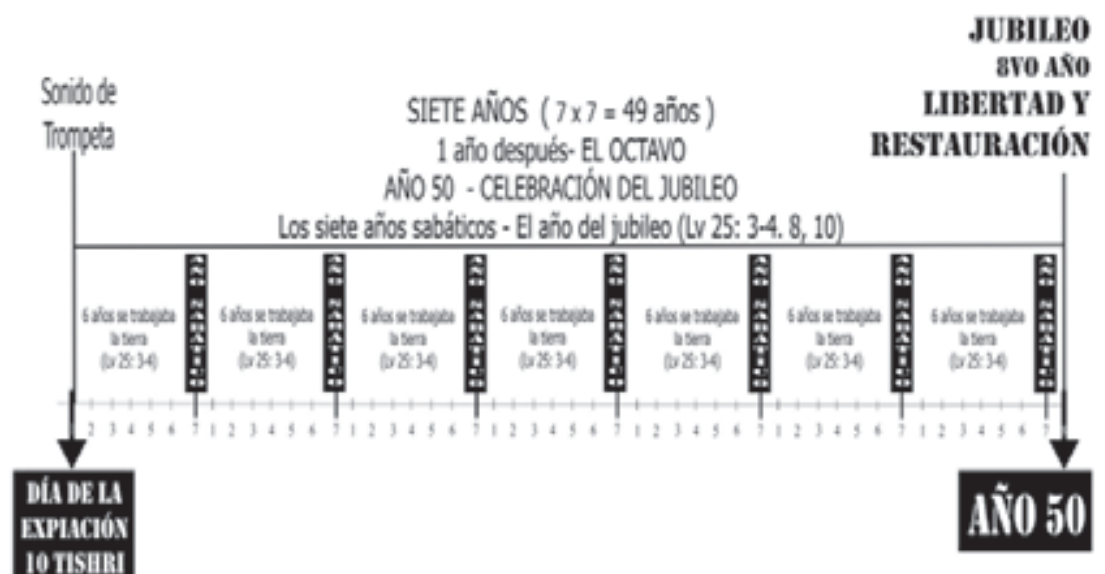

${ }^{17}$ Alomía, El año agradable de Jehová, 168.

${ }^{18}$ Ibid. 
Indudablemente que en todos los aspectos hasta aquí mencionados, el octavo ha sido relacionado con la obra de restauración, libertad, resurrección, celebración e instauración del reino de Dios. Esto involucra a la obra que Dios estableció desde que los primogénitos eran circuncidados al octavo. Después continuó con las tres fiestas que demandaban la presencia de todos los varones en el santuario, las tres santas convocatorias. Pero el octavo no queda allí.

En Apocalipsis hay dos textos que relacionan a Jesús con David. Cuando desarrolló su ministerio aquí en la Tierra, más de uno lo llamó, el hijo de David. Lo interesante de ello o la analogía que se presenta, es que David era el octavo hijo de Isaí. Lo que hace que tenga una vinculación interesante con el que ha de instaurar el reino fructífero y eterno. Apocalipsis 3:7 dice "el que tiene la llave de David", llevando una explicación lógica de la experiencia de un mayordomo de la casa de David (Is 22: 20-22; 2 R 18: 18).

Eliaquim fue nombrado para supervisar "la casa de David", como lo demuestra el hecho de que se le" daría "la llave de la casa de David". Esto tiene una relación con Cristo teniendo la "llave" la cual representa su autoridad sobre la iglesia y sobre el propósito divino que debía ser cumplido por ella (Mt 28: 18; Ef 1:22). Es decir, con "la llave de David", Cristo tiene plena autoridad para abrir y cerrar, para hacer triunfar el plan de la redención. ${ }^{19}$

La supremacía o prioridad de David, aun hasta del mismo Abraham, es vista en Mateo 1: 1. Apocalipsis 5: 5 describe que "la raíz de David, ha vencido para abrir el libro y sus siete sellos". Apocalipsis 22: 16, también dice: Yo soy la raíz y la descendencia de David”. El significado de esta expresión la encontramos si entendemos que David es considerado como uno de los mejores reyes y guerreros. Esos valientes que triunfan. Se lee así:

Este título proviene de Isa. 11: 1, 10, donde dice: "saldrá vara de la raíz de Isaí" (LXX) o "retoño del tronco de Isaí" (Heb.), o sea el padre de David. En Rom. 15:12 Pablo aplica este símbolo a Cristo, lo que muestra que Cristo es un segundo David. David

${ }^{19} \mathrm{CBA}, 7: 774$. 
fue el máximo rey y héroe militar de Israel. El concepto davídico del Mesías era esencialmente el de un vencedor que restauraría el reino de Israel (Mat. 21:9; cf. Hech. 1:6). Aunque Cristo no restauró el reino literal de los judíos, su victoria en el gran conflicto con Satanás restituirá el reino en un sentido infinitamente mayor y más importante. Por lo tanto, desde el punto de vista de este pasaje, este título es sumamente adecuado. ${ }^{20}$

Con este comentario se vuelve al entendimiento de por qué David fue una de las figuras que usan los israelitas en el tiempo de Jesús. En la entrada triunfal a Jerusalén, estas expresiones salieron de los labios de toda la muchedumbre, como un deseo de restauración del reino de Dios. Cristo viene como el guerrero victorioso, con la valentía de David a instaurar su trono. Esta figura nuevamente nos conecta con la obra de restauración del reino mesiánico.

La obra del templo tiene también algunas conexiones con el octavo, ya que se terminó de construir en "el año undécimo, en el mes de Bul, que es el mes octavo. La edificó, pues, en siete años" (1 R 6: 38). Según el registro, son 7 años y 6 meses, y el octavo año se procede a inaugurar el templo. Se hacen los acabados y se trasladan los utensilios y se deja todo en su lugar en un lapso de once meses. Si el reinado de Salomón fue en primavera, con Tishri, entonces la construcción del templo habría sido terminado el séptimo año ${ }^{21}$, instantáneamente después del octavo sería su inauguración y la fiesta.

En el mes séptimo, ocho años cinco meses, en "la fiesta" de las cabañas, se inaugura el templo como símbolo de establecimiento de un nuevo comienzo del reinado de Dios. "Comenzaron la santificación el primer día del mes primero, y el octavo día del mes entraron al pórtico del Señor; entonces santificaron la casa del Señor en ocho días, y terminaron el día dieciséis del mes primero" (2 Cr 29: 17).

Sin embargo la pregunta que brota es el sentido de la relación con

${ }^{20}$ Ibid., 7: 787.

${ }^{21}$ Lynn H. Wood y Siegfried H. Horn, "The Chronology of Ezra 7: A Report of the Historical Research Committee of the General Conference of Seventh-day Adventist" (Washington, DC: General Conference, 1953), 45. 
el octavo, esto es con Jesús. En primer lugar es el hecho lógico es que termina el octavo año y el octavo día. Pero no queda allí, el punto central es que aquí hay un tipo de Jesús. El templo debe verse en relación al templo espiritual, que se construye no con piedras muertas sino con piedras vivas, los seres humanos. La edificación del templo espiritual irá adelante, hasta que esté completo, y la piedra angular sea colocada con clamores: "Gracia, gracia a ella". (Zac 4: 7). ${ }^{22}$ El construir el templo espiritual, no tanto el material, fue el objetivo de Dios. El texto dice: "También vosotros, como piedras vivas, sed edificados como casa espiritual para un sacerdocio santo, para ofrecer sacrificios espirituales aceptables a Dios por medio de Jesucristo" (1 P 2: 5). En ese sentido la obra de este templo se termina cuando Jesús termina de hacer la obra en el ser humano. Este final llega en ocasión del establecimiento del reino de Dios, la Piedra que fue cortada del monte sin ayuda de manos (Dn 2: 45).

El templo judío fue construido con piedras labradas que se sacaron de las montañas. Y cada piedra era preparada para su lugar en el templo, labrada a escuadra, pulida y probada antes de ser transportada a Jerusalén. Cuando todas esas piedras se encontraron sobre el terreno, la edificación se hizo sin que se oyera el ruido de un hacha o de un martillo. Esta edificación representa el templo espiritual de Dios, compuesto de materiales traídos de todas las naciones, lenguas, pueblos y clases sociales, grandes y pequeños, ricos y pobres, sabios e ignorantes. No se trata de substancias inertes, que deban ser trabajadas por medio del martillo o el cincel. Son piedras vivas, sacadas de la cantera del mundo por medio de la verdad; y el gran Arquitecto, el Señor del templo, está ahora labrándolas y puliéndolas, preparándolas para su lugar respectivo en el templo espiritual. Ese templo, una vez terminado, será perfecto en todas sus partes y causará la admiración de los ángeles y de los hombres; porque Dios es su Arquitecto y Constructor. ${ }^{23}$

Es interesante mirar cómo cada detalle del templo fue diagrama-

${ }^{22}$ White, Joyas de los Testimonios, 3: 170.

${ }^{23}$ Ibid., 379. 
do, representando al templo espiritual de Dios, este simbolismo ayuda a comprender la importancia de esta edificación, representando el templo final o la ciudad santa, que un día será fundada, en el establecimiento del reino de Dios. Tomando el símbolo del "octavo" día, en donde el primogénito era separado y entregado a Dios, el templo en el octavo año es dedicado a Dios y su santificación duró ocho días. Véase el diagrama.

Diagrama 8: La inauguración del templo y el 8vo

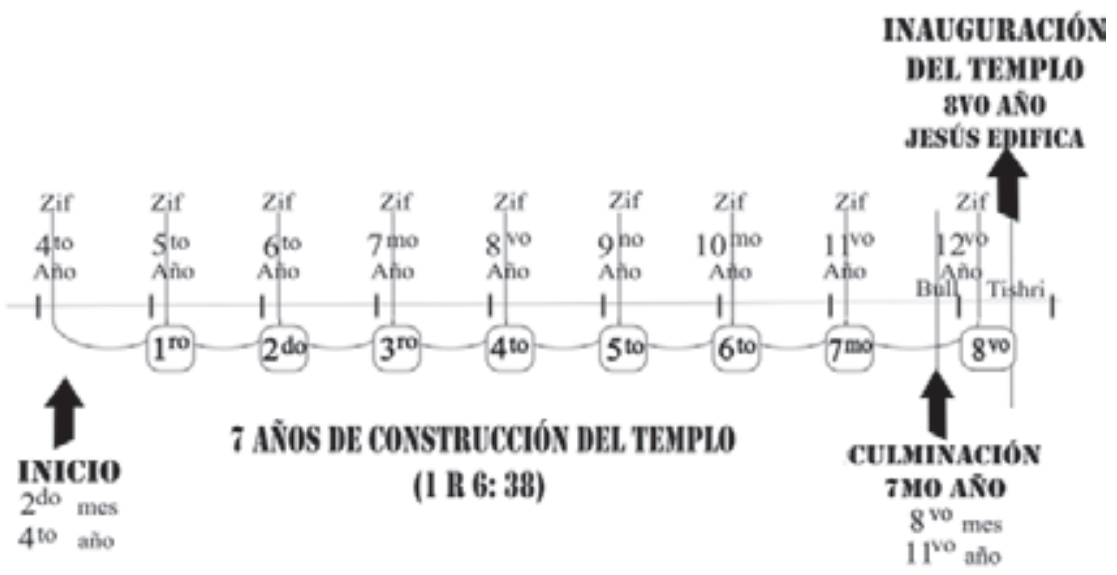

Un punto más que la Biblia muestra, y que ante la vista cuidadosa no puede pasar por alto, es la referencia a la estructura de la ciudad misma de Dios, que también está relacionada con el templo. Apocalipsis muestra a una ciudad en donde sus planos, altura, largo y ancho, son de la misma medida, creando un cubo perfecto. La descripción reza así: "Y la ciudad está asentada en forma de cuadro, y su longitud es igual que su anchura. Y midió la ciudad con la vara, doce mil estadios; y su longitud, anchura y altura son iguales" (Ap 21: 16).

Esto parte de las medidas que Ezequiel da del templo, formando también un cuadrado perfecto, con cuatro mil quinientos codos por lado, y en esos cuatro lados tres puertas (Ez 48: 31-35). El cuadro es el de una ciudad antigua con muros y puertas; eran términos con los cuales estaba familiarizado el profeta, y la inspiración escogió revelarle las glorias de la ciudad eterna en términos que él comprendía. En una profecía pictó- 
rica, el grado de identidad entre la escena que se presenta y la realidad exige una cuidadosa interpretación (ver com. Eze. 1: 10; 40: 1). Pero es en esta diagramación que se puede conectar el octavo, que es el símbolo por describir.

Diagrama 9: La relación de la ciudad de Apocalipsis 21:16 y el 8vo ${ }^{24}$

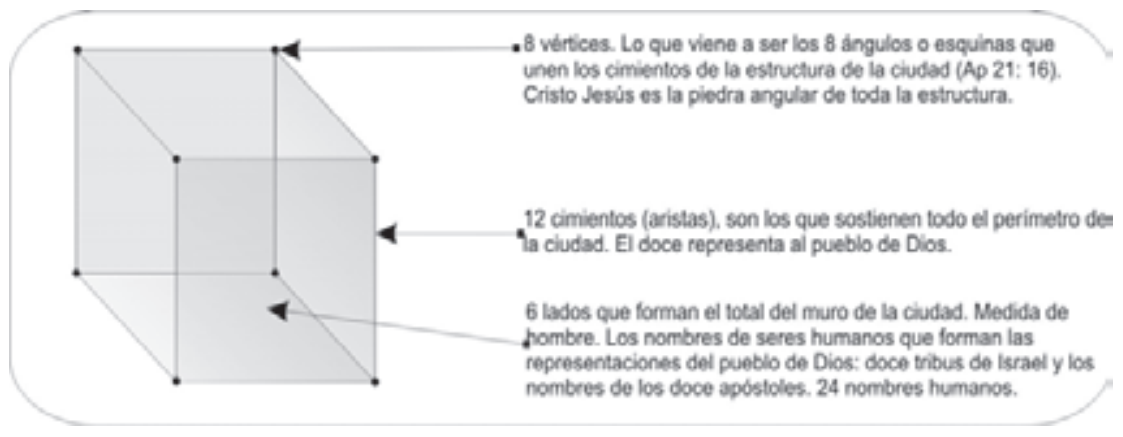

Se puede ver en este diagrama cómo aparecen las piedras angulares o vértices en un número relacionado con el octavo. Esta manifestación de 8 ángulos es un cumplimiento de lo que Job refiere del mismo Creador del planeta Tierra, "¿Sobre qué se asientan sus bases, o quién puso su piedra angular?" (Job 38: 6). Como dijo David, "La piedra que desecharon los edificadores ha venido a ser la piedra principal del ángulo" (Sal 118: 22; la cursiva es mía), también lo escribió Isaías diciendo: "Por tanto, así dice el Señor Dios: He aquí, pongo por fundamento en Sion una piedra, una piedra probada, angular, preciosa, fundamental, bien colocada. El que crea en ella no será perturbado" (Is 28: 16).

Aunque la Biblia habla de una sola piedra angular, en esta ciudad aparecen ocho ángulos. Esto se debe por un sentido de representación del "octavo" en el establecimiento de su reino. Ese octavo, en conclusión es Jesús. Basta con leer la Palabra "Edificados sobre el fundamento de los apóstoles y profetas, siendo Cristo Jesús mismo la piedra angular, en quien todo el edificio, bien ajustado, va creciendo para ser un templo santo en el Señor, en quien también vosotros sois juntamente edificados para morada de Dios

${ }^{24}$ E. Núñez, entrevista 25 de octubre de 2009. 
en el Espíritu" (Ef 2: 20-22). Por ello el nombre de Jesús, en griego es I $(I=10 ; \eta=8 ; \sigma=200 ; o=70 ; v=400 ; \varsigma=200)$, equivale a 888 .

Los ejemplos claros serían el 666 que intenta perpetuarse en el poder, el cual es la marca de la rebelión de la Bestia; y también el número ya mencionado, y que encuentra relación con todo lo visto hasta aquí sobre el 888, que simboliza la victoria eterna, con el establecimiento de los cielos nuevos y la tierra nueva. Es el establecimiento del reino de Dios.

Esto termina de aclarar el asunto: es Jesús quien se prepara para establecer el reino final, la octava etapa de la iglesia. Podríamos decir en referencia a las siete iglesias, es el octavo reino, el que establece un reino que no tendrán fin, y como dice Daniel, cubrirá toda la tierra. Entonces la conclusión es que el número ocho representa a Jesús, al nuevo comienzo y a su obra restauración final. La salvación, la purificación y la resurrección.

Por esta razón inclusive White trasmite en repetidas ocasiones que el tiempo destinado a este mundo está ligado a seis mil años. Es la oportunidad del hombre, son los años que podrá tener para proceder al arrepentimiento.

El séptimo período, es un milenio de descanso, así como los siete días de la "fiesta de las cabañas", en donde se acampará con Jesús y se gozará el cielo con la cosecha. Pero al octavo día, es gran santa asamblea, ya que Cristo Jesús establece su Reino Eterno, es la Piedra Angular, es la base de la Ciudad Santa que desciende triunfante.

Apocalipsis 21: 4 dice: "El enjugará toda lágrima de sus ojos, y ya no habrá muerte, ni habrá más duelo, ni clamor, ni dolor, porque las primeras cosas han pasado". Esto se cumple al final del séptimo milenio, y se inicia el octavo milenio renovando, haciendo nuevas todas las cosas. Como es una frase en la lógica profética, Satanás la ha intentado desvirtuar con "las teorías de los 6000 años de la evolución teísta Sin embargo es tan grande el énfasis de White, que ella ve en visión a los redimidos en el cielo, y desde ese presente escatológico expresa declaraciones nítidas de los años vividos en este planeta de sufrimiento que pasaron en la tierra. En las primeras citas ella mira con anhelo, que cerca a seis mil años Satanás ha logrado crear el dolor y sufrimiento. En las otras citas, ella lo hace en forma retrospectiva, de un momento futuro de la visión. 
La gran controversia entre Cristo y Satanás, sostenida desde hace cerca de seis mil años, está por terminar; y Satanás redobla sus esfuerzos para hacer fracasar la obra de Cristo en beneficio del hombre y para sujetar las almas en sus lazos. ${ }^{25}$

La continua transgresión del hombre durante seis mil años ha producido enfermedad, dolor y muerte. ${ }^{26}$

Durante seis mil años, Satanás luchó por mantener la posesión de la tierra. Pero se cumplirá el propósito original de Dios al crearla. "Tomarán el reino los santos del Altísimo, y poseerán el reino hasta el siglo, y hasta el siglo de los siglos". ${ }^{27}$

Como siempre, un diagrama puede ilustrar mejor estos conceptos.

Diagrama 10: El 8vo milenio y el establecimiento del Reino Eterno de Dios.

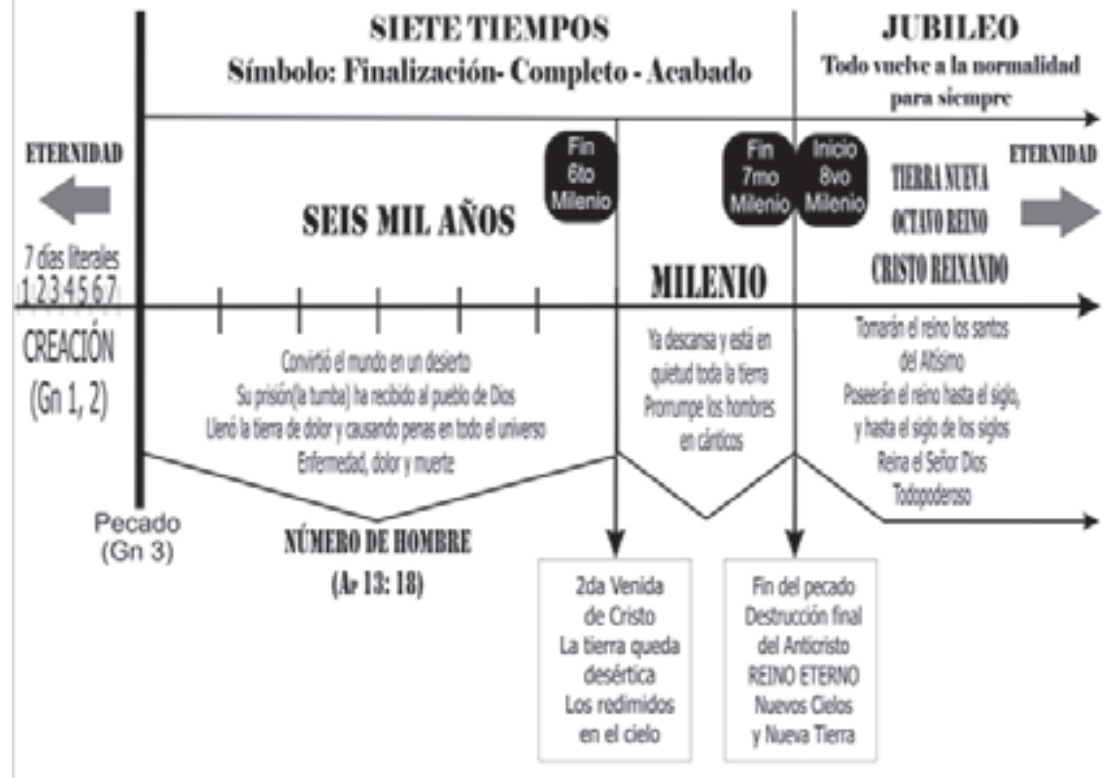

${ }^{25}$ White, Conflicto de los siglos, 572.

${ }^{26}$ White, Joyas de los testimonios, 1: 423.

${ }^{27}$ White, Patriarcas y profetas, 355. 
El conectar estas citas en este esquema, ayuda a entender el por qué Dios no acaba o finaliza con el pecado, en su segunda venida. Dios es un Dios que maneja principios y aunque no está ligado al tiempo, hace que éstos se cumplan por respeto a los simbolismos ya determinados por él mismo. Entonces, como las profecías septenarias, las siete iglesias, los siete sellos, las siete trompetas, las siete plagas, las siete cabezas, cuando llega el momento o el tiempo de la última es la finalización de la misma, no hay forma que el hombre agregue un tiempo más. El tiempo ha sido marcado y Dios no cambia, ni se muda. Él cumplirá todo lo que ha establecido en su Palabra.

\section{Descubriendo el misterio del "octavo" con la bestia de siete cabezas}

Pero qué tiene que ver la descripción bíblica, vista en la sección anterior, con la bestia de Apocalipsis 17. La respuesta es obvia, el texto 11, expresa así: "Y la bestia que era y no es, éste es octavo, y es uno de los siete y va a la destrucción". Entonces podemos explicar algunos argumentos para su interpretación.

En conclusión, no es una nueva cabeza; el texto dice: es el octavo rey. Por lo que no es justo pensar que aquí Juan intenta poner en la escena un octavo reino, porque él sabe que el octavo reino, en el contexto escatológico, está conectado con el reino de Cristo Jesús. Lo que sí quiere desarrollar y desenmascarar es la astucia del impostor, el Anticristo, que quiere formar ese reino en esta tierra, según él, bajo la autoridad de Dios, pero lo hace con la autoridad satánica, el "inicuo cuya venida es conforme a la actividad de Satanás, con todo poder y señales y prodigios mentirosos" (2 Ts 2: 9).

El plan del Anticristo elimina la posibilidad de una segunda venida de Cristo, tal como lo dicen las Escrituras. Si el reino de Dios, ya se estableció en la tierra, Jesús ya no tiene la necesidad de presentarse. El Anticristo, en esta etapa de "será", intenta hacer todo lo que haría Jesús si estuviera aquí en la tierra. Se proclama el jubileo, la paz y la armonía de los pueblos. Aparentemente el espíritu mismo de Cristo está presente en este poder bestial.

Por último, el hecho que las características de Jesús, “es, era y ha de venir" (Ap 1:4, 8, 18), están relacionadas con las del Anticristo, "era, 
y no es y saldrá del abismo" (Ap 17:8), da la idea concluyente de una manifestación directa de Satanás, en donde se cumpla la declaración bíblica "presentándose como si fuera Dios" (2 Ts 2: 4c). La siguiente cita da la idea de un sentido más amplio para la interpretación de esta de la osadía que tiene Satanás de creerse Dios. El comentario de este versículo, propone también lo que se viene diciendo en esta investigación.

El poder que aquí se describe puede identificarse en un sentido más amplio con Satanás, quien por muchísimo tiempo se ha esforzado por ser "semejante al Altísimo" (ver com. Isa. 14: 14). "Satanás está obrando con suma intensidad para presentarse como Dios, y para destruir a todos los que se oponen a su poder. Y hoy el mundo se está postrando delante de él. Se recibe su poder como poder de Dios" (2JT 369). "La resolución del anticristo de llevar a cabo la rebelión empezada por él en el cielo, continuará animando a los hijos de desobediencia" (3JT 393394). "En esta época aparecerá el anticristo como si fuera el Cristo verdadero, y entonces la ley de Dios será completamente invalidada... Pero el verdadero director de toda esta rebelión es Satanás vestido como un ángel de luz. Los hombres serán engañados y lo exaltarán en lugar de Dios, y lo deificarán" (TM 62). "El último gran engaño se desplegará pronto ante nosotros. El anticristo va a efectuar ante nuestra vista obras maravillosas" (CS 651). ${ }^{28}$

Entonces en este enfoque, el Anticristo no es sólo el papado, sino ante todo es Satanás, el Anticristo supremo, personificando a Cristo al final de los tiempos. Entonces el "anticristo" original y por antonomasia es Satanás, quien siempre se ha opuesto a Cristo con la ayuda de varios instrumentos humanos. Muchos siglos antes de que el hombre fuera creado, Satanás intentó desplazar a Cristo (Is 14: 12-14; Eze 28: 12-13), y desde entonces ha inspirado sin cesar toda oposición contra Dios y su Hijo Jesucristo (2 Tes. 2: 8-9). ${ }^{29}$

${ }^{28} \mathrm{CBA}, 7: 279$.

${ }^{29}$ Ibid. 
Como Satanás se ha incorporado a sí mismo en la Bestia, es que su manifestación como octavo completará la suma de todas las atrocidades históricas del mundo. Pero a la vez desfigurará el engaño de su continuo accionar a través de estos seis mil años de existencia del pecado. Al hablar el ángel del "octavo rey" como procedente de los otros siete, lo hace en el sentido de señalar al que estuvo detrás de todas bestialidades que se cometieron en la historia de este mundo. Sin embargo, esta apreciación también nos indica que su aparición sería en el último momento de la historia. Entonces el genio del mal y la mentira estuvo presente en forma engañosa en todos aquellos que creyeron que gobernaban como dioses, cuando eran sólo cabezas manipuladas por el gran artífice del mal. Todos estos imperios fueron sus instrumentos, con ellos estableció su filosofía de gobierno y autoridad.

Casi todas las denominaciones han hecho de lado la creencia bíblica que describe Pablo cuando dice "seremos arrebatados... para recibir al Señor en el aire" (1 Ts 4:17), para preparar la falsa "venida de Jesús", en la cual el mismo Satanás actuará en nombre de Jesús. ${ }^{30}$

${ }^{30}$ Para un mayor estudio, ver Erik Jiménez, "La bestia de Apocalipsis 17 y la aparición de Satanás en la tierra”, Estrategias 6, no. 1 (2009): 18-20. 